\title{
Dietary Inflammatory Index and Cardiometabolic Risk Parameters in Overweight and Sedentary Subjects
}

\author{
Claudia Marcela Camargo-Ramos ${ }^{1}$, Jorge Enrique Correa-Bautista ${ }^{1}$ (D), \\ María Correa-Rodríguez ${ }^{2}$ (D) and Robinson Ramírez-Vélez ${ }^{1, *}$ (D) \\ 1 Centro de Estudios para la Medición de la Actividad Física (CEMA), Escuela de Medicina y Ciencias de la \\ Salud, Universidad del Rosario, Bogotá DC 111221, Colombia; camargoclaudia88@gmail.com (C.M.C.-R); \\ jorge.correa@urosario.edu.co (J.E.C.-B.) \\ 2 Departamento de Enfermería, Facultad de Ciencias de la Salud Avda, De la Ilustración, s/n, (18016), \\ Universidad de Granada, Granada 18071, Spain; macoro@ugr.es \\ * Correspondence: robin640@hotmail.com; Tel.: +57-129-702-00 (ext. 3428)
}

Received: 3 September 2017; Accepted: 21 September 2017; Published: 6 October 2017

\begin{abstract}
Nutrition has been established as a relevant factor in the development of cardiovascular disease (CVD). We aimed to investigate the relationship between the dietary inflammatory index (DII) and cardiometabolic risk parameters in a cohort of 90 overweight and sedentary adults from Bogotá, Colombia. A 24-h dietary record was used to calculate the DII. Body composition variables, flow-mediated dilation (FMD), pulse wave velocity (PWV), lipid profile, glucose, glycosylated hemoglobin $(\mathrm{Hb} 1 \mathrm{Ac})$, and blood pressure were measured and a cardiometabolic risk score (MetScore) was calculated. A lower DII score (anti-inflammatory diet) was significantly associated with higher high-density lipoprotein-cholesterol (HDL-C) and FMD, and lower Hb1Ac and MetScore $(p<0.05)$. A lower DII score was inversely correlated with plasma triglyceride levels $(r=-0.354, p<0.05)$, glucose $(r=-0.422, p<0.05)$, MetScore $(r=-0.228, p<0.05)$, and PWV $(r=-0.437, p<0.05)$, and positively with FMD $(r=0.261, p<0.05)$. In contrast, a higher DII score (pro-inflammatory diet) showed a positive relationship with MetScore $(r=0.410, p<0.05)$ and a negative relationship with FMD $(r=-0.233, p<0.05)$. An increased inflammatory potential of diet was inversely associated with an improved cardiometabolic profile, suggesting the importance of promoting anti-inflammatory diets as an effective strategy for preventing CVD.
\end{abstract}

Keywords: dietary inflammatory index; cardio-metabolic; diet; overweight

\section{Introduction}

Low-grade chronic inflammation has been established as a relevant factor in the development of cardiovascular disease (CVD) [1]. It is characterized by increased circulating levels of cytokines with inflammatory activity and acute-phase proteins (C-Reactive Protein; CRP), interleukins (IL-1, IL-6), and tumor necrosis factor alpha (TNF- $\alpha$ ), among others-as well as by increased infiltration of macrophages in peripheral tissue [2]. Evidence has shown that lifestyles, especially dietary factors, may modulate this process [3-5]. Thus, nutrition plays an important role in the development of atherogenesis and cardiovascular events $[3,6]$.

In this context, it has been indicated that dietary patterns characterized by a high intake of saturated and trans unsaturated fatty acids may lead to alterations in endothelial function $[7,8]$. The "Western" diet, rich in red meats, fats, and carbohydrates, has been positively associated with markers of low-grade subclinical inflammation, while dietary patterns based on fruits, vegetables, olive oil, and whole grains have shown an inverse relationship [3,4,9]. In addition, the Mediterranean 
food pattern, which is a well-known anti-inflammatory diet, exerts a protective effect against free radicals and oxidants [10].

A dietary pattern comprising high amounts of fish, yogurt, vegetables, pasta, greens, fruit, and wine also has the potential to reduce circulating levels of inflammatory markers [3]. Diet-based anti-inflammatory components, including omega-3 fatty acids, vitamins B1 (thiamine), B2 (riboflavin) and B3 (niacin), folic acid, vitamin A, vitamin C, vitamin E, beta-carotene, magnesium, and zinc, have been identified [11].

On this basis, researchers from the University of South Carolina in the United States designed the dietary inflammatory index (DII), a tool for assessing the inflammatory diet profile based on 45 nutritional parameters. Due to their anti-inflammatory or pro-inflammatory properties, these nutritional factors were associated with markers of inflammation including CRP, interleukins IL-1 $\beta$, IL-4, IL-6 and IL-10, and TNF- $\alpha$ [12]. The DII has been reported to be associated with several inflammatory processes, such as obesity, insulin resistance, cardiovascular risk, and several types of cancer [13-16]. However, to the best of our knowledge, the DII has not been used to evaluate inflammatory properties of diet in Latin Americans, characterized by increasing total fat, animal products, and sugar intakes [14], particularly in the Colombian population. Since Latin Americans have different dietary habits and morbidity and mortality indicators, it is of particular interest.

Recently, there has been a surge of interest in developing strategies with a more cost-effective approach and fewer side effects, which is useful in clinical practice aimed at preventing CVD. Among the non-pharmacological strategies, physical activity and diet are considered the cornerstones of cardiovascular prevention. Taking all this evidence into account, we aimed to investigate the relationship between the DII and cardiometabolic risk parameters in a cohort of overweight and sedentary adults from Bogotá, Colombia.

Our hypothesis is that higher DII scores (pro-inflammatory diet defined by positive values) are associated with an increased cardiometabolic risk profile, independently of other risk factors such as age and gender.

\section{Materials and Methods}

\subsection{Study Design}

A secondary analysis of the clinical trial High Intensity Interval- vs. Resistance or CombinedTraining to Improve Cardiometabolic Health in Overweight Adults: Cardiometabolic HIIT-RT Study ClinicalTrials.gov Identifier: NTC02715063 was carried out between 2016 and 2017 [17]. The study was performed in accordance with the Declaration of Helsinki (2000) and was approved by the Human Ethics Committee of Manuela Beltrán University (Code N 06-1006-2014; Resolution 008430/2003 by the Colombian Ministry of Health). Written informed consent was obtained from each participant.

\subsection{Participants}

The sample comprised 90 women and men, with excess body weight (BMI $\geq 26$ and $\leq 35 \mathrm{~kg} / \mathrm{m}^{2}$ ), who were sedentary (individuals who do not engage in five or more days of moderate physical activity or walking for at least $30 \mathrm{~min}$ per session, or who do not engage in three or more days per week of vigorous physical activity for $20 \mathrm{~min}$, as assessed by the International Physical Activity Questionnaire (IPAQ) [18], and who met at least one of the criteria of metabolic syndrome as established by the International Diabetes Federation [18]. The study cohort was selected through a call for volunteers. Exclusion criteria included medical diagnosis of hypertension, hypo/hyperthyroidism, history of alcohol and drug abuse, use of lipid-lowering medications, or drugs capable of modifying the lipid profile four weeks before the study, following hypocaloric diets to lose weight and suffering from inflammatory or infectious processes. 


\subsection{Procedures}

Participants completed questionnaires regarding medical history including personal and family history of CVD, smoking status (number of cigarettes/day), alcohol consumption (grams of alcohol/day), physical activity (min/week), and medication use.

Anthropometric measurements, including height, weight, waist circumference (WC), and hip circumference (HC), were evaluated according to standardized protocols for the Colombian population established by the World Health Organization (WHO) [19]. Height was measured to the nearest $0.1 \mathrm{~cm}$ using a portable stadiometer (SECA $206^{\circledR}$, range 0-220 cm, Seca GmbH \&. Co, Hamburg, Germany). To measure weight, we used an electronic scale (Seca mBCA $515^{\circledR}$ HANS E. RÜTH S.A, Allers Co, Hamburg, Germany). Body mass index (BMI) was calculated as weight over height squared $\left(\mathrm{kg} / \mathrm{m}^{2}\right)$. An anthropometric a metal tape (Lufkin W606PM ${ }^{\circledR}$, Allers Co, Parsippany, NJ, USA), with an accuracy of $\pm 1 \mathrm{~mm}$ was used to measure hip circumferences according to anatomical references established by the WHO [20]. Body composition parameters, including fat and lean mass in grams and percentage (trunk, gynecoid, android, android/gynecoid (A/G) fat quotient) and total tissue, were measured by dual-energy X-ray absorptiometry (DXA, Hologic Mod Explorer ${ }^{\circledR}, 4500$ C/W QDR, INC 35 Crosby Drive, Bedford, USA), and the regions of interest (ROIs) were selected. These measurements were performed after $10-12 \mathrm{~h}$ of fasting.

Blood pressure was taken with an automatic monitor (Omrom ${ }^{\circledR}$ HEM 705 CP, Health-care Co, Kyoto, Japan) following the recommendations of the European Heart Society (on the right arm, with participants in a supine position and after $10 \mathrm{~min}$ of rest). Mean arterial pressure (MAP) was calculated using the following formula: (2 (systolic blood pressure (SBP) + diastolic blood pressure (DBP))/3).

Capillary blood samples $(40 \mu \mathrm{L})$ were collected for determining serum biochemical parameters, including fasting glucose, triglycerides (TG), high-density lipoprotein-cholesterol (HDL-C), and total cholesterol (TC) using portable Cardiocheck ${ }^{\circledR}$ equipment (Mexglobal SA, Parsippany, NJ, USA). Low-density lipoprotein-cholesterol (LDL-c) was calculated using Friedewald's Formula when triglyceride values were $\leq 400 \mathrm{mg} / \mathrm{Dl}$ [21]. Glycated hemoglobin (Hb1Ac) was measured using A1cNow $+\left(\right.$ Bayer $^{\circledR}$, Mexglobal SA, Terrytown, NY, USA). Blood samples were drawn between 07:00 and 09:00, after 10-12 h of fasting (11.2 h on average). A cardiometabolic risk score (MetScore) was calculated as the sum of the typified Z-scores per age and gender from the following components: WC, TG, HDL-C, glucose, and MAP [18]. MetScore $=\left(\left(0^{\top} 40\right.\right.$ or $\left.\left.950-\mathrm{HDL}-\mathrm{C}\right) / \mathrm{SD} \times(-1)\right)+(($ triglycerides $-150) / \mathrm{SD})+(($ glucose -100$) / \mathrm{SD})+\left(\left(\mathrm{WC}-0^{\top} 90\right.\right.$ or 980$\left.) / \mathrm{SD}\right)+((\mathrm{MAP}-100) / \mathrm{SD})$. Cut-off points to calculate the MetScore were determined according to the International Diabetes Federation criteria [18]. A MetScore standard deviation score $\geq 1$ was considered to represent a high risk of CVD.

Brachial artery flow-mediated dilation (FMD) was used as a measure of endothelium-dependent vasodilation. The peripheral vessel ultrasound evaluation was performed with a high-resolution ultrasound system (Mindray M-9 ${ }^{\circledR}$, Invermedica LTDA, Shenzhen, China), with a 7.5 MHz linear array probe to locate and interrogate flow velocity profiles in the right brachial artery. Ultrasound images were obtained after $20 \mathrm{~min}$ of rest in a supine position in a dark, climate-controlled, quiet room $\left(22-24{ }^{\circ} \mathrm{C}\right)$, with the participant's arm immobilized and slightly supinated and elevated. An additional $10 \mathrm{~min}$ of rest was allowed before the opposite arm was imaged. The right arm was imaged first in each case. After a resting period of at least $20 \mathrm{~min}, 1 \mathrm{~min}$ of baseline recording of the brachial artery diameter was performed. Subsequently, the occlusion cuff was inflated to $>200 \mathrm{mmHg}$ for $5 \mathrm{~min}$ [22]. To estimate brachial artery shear stress, peak shear rate was calculated as follows: peak SR = maximal flow velocity $(\mathrm{mm} / \mathrm{s}) /$ baseline diameter $(\mathrm{mm})$. Normalized brachial artery FMD was calculated to account for the peak shear rate using the following equation: normalization of brachial artery flow-mediated dilation $($ FMDn $)=$ brachial artery FMD / peak shear rate $\times 100$. Brachial artery diameter recording was restarted at least $30 \mathrm{~s}$ before cuff deflation and continued for $3 \mathrm{~min}$ thereafter. Peak artery diameter and the time to reach this peak after cuff deflation were recorded. The intra-session coefficient of variations was $\leq 1 \%$ for the baseline diameter. Reliability, estimated by intra-class correlation coefficients (ICCs) 
based on four baseline measurements ( $n=8$ subjects), showed an ICC of 0.91 for baseline diameter and 0.83 for FMD.

Aortic pulse wave velocity (PWV) was measured with the oscillometric method using the occlusion technique [23] by Arteriograph (TensioMedTM software v 1.9.9.2, Mexglobal SA, Budapest, Hungry). A detailed description of the PWV technique can be found elsewhere [23]. Outcome measures were assessed by personnel blinded.

\subsection{Dietary Inflammatory Index}

The DII was calculated from 28 food parameters, including carbohydrates, proteins, fats, fiber, iron, zinc, magnesium, vitamin A, vitamin $C$, vitamin B6, vitamin B12, vitamin $E$, vitamin $D$, thiamine, riboflavin, niacin, selenium, folic acid, saturated fats, monounsaturated fats, polyunsaturated fats, omega 3 fatty acids, omega 6 fatty acids, trans-type fatty acids, $\beta$-carotene, and caffeine. Food consumption was estimated from a $24 \mathrm{~h}$ dietary record (mean between one weekday and one weekend day). Data were checked by a nutritionist, and standard household measures were used. DII scores were recoded as a pro-inflammatory diet (positive values) or anti-inflammatory diet (negative values) based on previous studies [24].

\subsection{Statistical Analysis}

All statistical analyses were performed using the Statistical Package for the Social Sciences ${ }^{\circledR}$ software, version 22 for Windows (SPSS ${ }^{\circledR}$, Inc., IBM, Chicago, IL, USA). The Kolmogorov-Smirnov normality test was conducted before association analysis. Continuous variables were presented as mean \pm standard deviation and categorical variables were presented as frequencies and percentages ( $n$ and \%). The differences were estimated using Student's $t$ - or chi-square tests depending on the type of variable. DII scores were recoded as a pro-inflammatory diet (positive values) $(\geq 2.03, \mathrm{~min} / \max (0.13$ to 3.64$) ; n=77)$ or anti-inflammatory diet (negative values) $(\leq-1.26$, $\min / \max (-3.71$ to -0.37$) ; n=13)$. Partial Pearson correlation coefficients between the DII and the cardiometabolic risk parameters adjusted for age and gender were performed. The significance level was set at $p<0.05$. The DII score ranged between -3.71 and 3.64 .

\section{Results}

The anthropometric, body composition, metabolic markers, and endothelial function variables assessed in this study are shown according to the categories of the DII score in Table 1 . The mean age of the study population was $39.7 \pm 6.9$ years and the mean BMI was $30.0 \pm 3.5 \mathrm{~kg} / \mathrm{m}^{2}$. Lower DII score (anti-inflammatory diet) was significantly associated with higher HDL-C ( $38.7 \mathrm{mg} / \mathrm{dL} \pm 9.2)$ and FMD $(12.3 \% \pm 7.9)$ and lower Hb1Ac $(5.3 \% \pm 0.5)$ and MetScore $(p<0.05)$. For the anthropometric, body composition, and blood pressure measurements, no significant differences among the categories of the DII were identified. Statistically significant differences were identified between the categories of the DII and normalized brachial artery FMD (Figure 1).

Table 2 shows the macro- and micronutrients intakes according to the categories of the DII. Higher intakes of fiber, iron, zinc, magnesium, vitamin A, vitamin C, thiamine, riboflavin, niacin, omega 3 , vitamin B6, folic acid, vitamin B12, beta-carotene, vitamin $\mathrm{E}$, and vitamin $\mathrm{C}$ were observed in the anti-inflammatory category compared to the pro-inflammatory category $(p<0.05)$. 


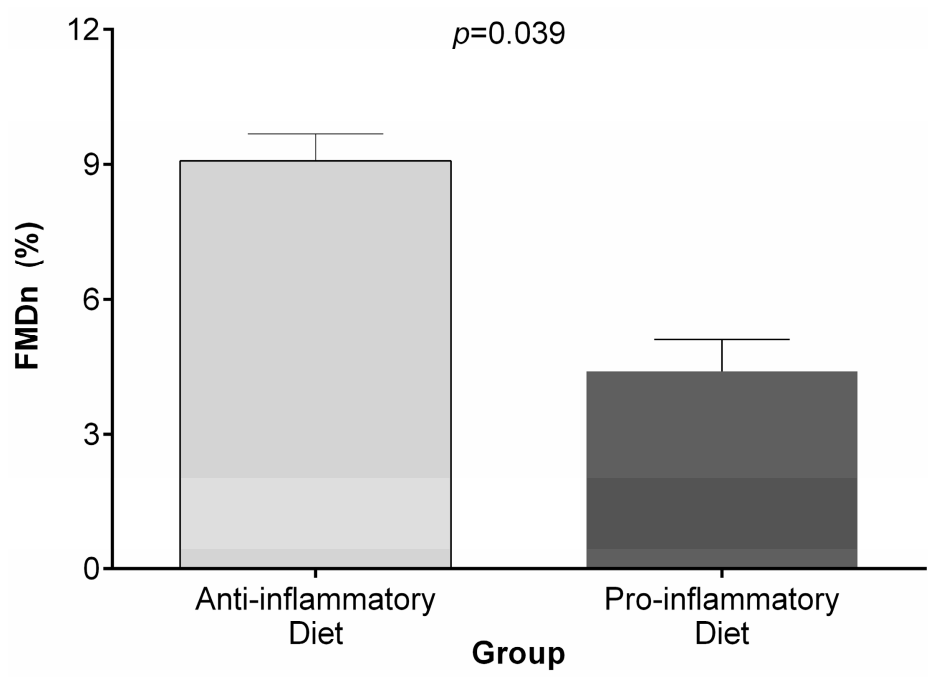

Figure 1. Differences among the categories of the dietary inflammatory index (DII) and normalized brachial artery flow-mediated dilation (FMD).

Table 1. Anthropometric characteristics, body composition, metabolic biomarkers, and endothelial function variables according to the categories of the DII.

\begin{tabular}{|c|c|c|c|}
\hline Characteristic & $\begin{array}{c}\text { Anti-Inflammatory } \\
\text { Diet }(n=13)\end{array}$ & $\begin{array}{l}\text { Pro-Inflammatory } \\
\text { Diet }(n=77)\end{array}$ & $p$ Value \\
\hline \multicolumn{4}{|l|}{ Anthropometry } \\
\hline Age (years) & $39.2(7.2)$ & $39.8(6.9)$ & 0.756 \\
\hline Weight (kg) & $78.6(13.7)$ & $79.9(11.6)$ & 0.497 \\
\hline Height $(\mathrm{cm})$ & $164.3(9.5)$ & $162.4(7.7)$ & 0.206 \\
\hline Waist circumference (cm) & $90.3(10.1)$ & $92.7(9.3)$ & 0.815 \\
\hline Hip circumference $(\mathrm{cm})$ & $105.9(6.7)$ & $106.5(8.2)$ & 0.327 \\
\hline Body mass index $\left(\mathrm{kg} / \mathrm{m}^{2}\right)$ & $28.9(2.8)$ & $30.2(3.6)$ & 0.245 \\
\hline \multicolumn{4}{|l|}{ Nutritional state } \\
\hline Overweight $n(\%)$ & $8(61.5)$ & $41(53.2)$ & 0.714 \\
\hline Obesity $n(\%)$ & $5(38.5)$ & $36(46.8)$ & 0.461 \\
\hline \multicolumn{4}{|l|}{ Body composition } \\
\hline DXA trunk tissue (\% fat) & $41.4(5.3)$ & $43.7(5.9)$ & 0.437 \\
\hline DXA trunk lean $(\mathrm{g})$ & $21,913.1(4418.1)$ & $21,458.6(3425.7)$ & 0.105 \\
\hline DXA gynecoid tissue (\% fat) & $37.6(8.7)$ & $39.5(8.7)$ & 0.944 \\
\hline DXA gynecoid lean $(\mathrm{g})$ & $7405.9(1909.5)$ & $7087.2(1307.0)$ & 0.113 \\
\hline DXA android tissue (\% fat) & $44.0(5.8)$ & $46.3(6.3)$ & 0.424 \\
\hline DXA android lean $(\mathrm{g})$ & $3237.4(662,9)$ & 3196.8 (521.9) & 0.393 \\
\hline DXA total tissue (\% fat) & $38.2(6.2)$ & $39.5(6.5)$ & 0.677 \\
\hline DXA total tissue (kg lean mass) & $46.7(10.6)$ & $45.9(8.0)$ & 0.065 \\
\hline Quotient trunk/total & $0.54(0.05)$ & $0.55(0.06)$ & 0.306 \\
\hline Quotient legs/total & $0.32(0.06)$ & $0.31(0.06)$ & 0.598 \\
\hline Quotient arms + legs/trunk & $0.80(0.19)$ & $0.77(0.21)$ & 0.561 \\
\hline Quotient tissue android/gynecoid & $1.20(0.24)$ & $1.20(0.24)$ & 0.948 \\
\hline Appendicular index $\left(\mathrm{kg} / \mathrm{m}^{2}\right)$ & $7.7(1.2)$ & $7.9(1.1)$ & 0.394 \\
\hline Fat-free lean mass index $\left(\mathrm{kg} / \mathrm{m}^{2}\right)$ & $10.5(2.4)$ & $11.5(3.0)$ & 0.380 \\
\hline \multicolumn{4}{|l|}{ Metabolic markers } \\
\hline $\mathrm{TC}(\mathrm{mg} / \mathrm{dL})$ & $162.8(30.2)$ & $159.2(38.1)$ & 0.373 \\
\hline Triglycerides (mg/dL) & $158.9(87.8)$ & $194.5(121.8)$ & 0.379 \\
\hline HDL-C (mg/dL) & $38.7(9.2)$ & $31.8(5.1)$ & 0.010 \\
\hline LDL-C (mg/dL) & $99.8(33.7)$ & $94.1(27.9)$ & 0.372 \\
\hline Glucose (mg/dL) & $87.7(8.1)$ & $92.5(11.9)$ & 0.070 \\
\hline MetScore & $-0.176(2.783)$ & $1.812(2.356)$ & 0.017 \\
\hline $\mathrm{HbAc1}(\%)$ & $5.3(0.5)$ & $5.8(0.4)$ & 0.003 \\
\hline
\end{tabular}


Table 1. Cont.

\begin{tabular}{cccc}
\hline Characteristic & $\begin{array}{c}\text { Anti-Inflammatory } \\
\text { Diet }(\boldsymbol{n = 1 3})\end{array}$ & $\begin{array}{c}\text { Pro-Inflammatory } \\
\text { Diet }(\boldsymbol{n}=\mathbf{7 7})\end{array}$ & $\boldsymbol{p}$ Value \\
\hline Markers of endothelial function & & & \\
\hline FMD (\%) & $12.3(7.9)$ & $6.7(5.4)$ & 0.015 \\
Baseline diameter, mm & $3.2(0.5)$ & $3.1(0.3)$ & 0.490 \\
Reactive hyperemia diameter, $\mathrm{mm}$ & $3.6(0.7)$ & $3.3(0.4)$ & 0.029 \\
Baseline flow velocity, cm/s & $80.4(24.5)$ & $81.9(24.0)$ & 0.836 \\
Reactive hyperemia diameter, flow velocity, cm/s & $152.8(33.5)$ & $135.3(35.2)$ & 0.107 \\
Peak Shear rate, s & $483.2(118.0)$ & $423.6(99.9)$ & 0.054 \\
PWV (m/s) & $7.0(0.6)$ & $7.3(1.1)$ & 0.082 \\
Aortic systolic pressure (mm Hg) & $110.7(6.8)$ & $111.0(11.2)$ & 0.889 \\
Aortic pulse pressure (mm Hg) & $39.1(6.3)$ & $38.8(7.4)$ & 0.886 \\
Brachial augmentation index (\%) & $20.6(11.4)$ & $23.7(19.0)$ & 0.435 \\
Aortic augmentation index (\%) & $-33.6(22.4)$ & $-20.8(27.2)$ & 0.082 \\
\hline Blood pressure & & & \\
\hline SBP (mm Hg) & $115.3(9.7)$ & $117.5(7.5)$ & 0.335 \\
DBP (mm Hg) & $71.5(7.2)$ & $72.2(9.7)$ & 0.767 \\
MAP (mm Hg) & $87.0(6.5)$ & $86.6(9.2)$ & 0.884 \\
\hline
\end{tabular}

Data are shown as mean \pm SD or frequencies $n(\%)$. The categories of the DII were compared using Student's $t$-tests for continuous variables and chi-squared tests for categorical variables. DXA: Dual energy X-ray absorptiometry; TC: total cholesterol; c-HDL-C: high-density lipoprotein-cholesterol; LDL-C: low-density lipoprotein cholesterol; Hb1Ac: glycated hemoglobin; FMD: flow-mediated vasodilation; PWV: pulse wave velocity; SBP: systolic blood pressure; DBP: diastolic blood pressure; MAP: mean arterial pressure. The MetScore was calculated from the sum of the typified residuals $(\mathrm{Z})$ of cardiovascular risk variables: $\left(\left(0^{\top} 40\right.\right.$ or $950-$ HDL-C)/SD $\left.\left.\times(-1)\right)\right)+$ $(($ triglycerides -150$) / S D)+(($ glucose -100$) / S D)+\left(\left(C C-0^{7} 94\right.\right.$ or $\left.\left.\$ 80\right) / S D\right)+((M A P-100) / S D$, adjusted for gender and age.

Table 2. Nutrient intake according to the categories of the DII.

\begin{tabular}{|c|c|c|c|}
\hline Nutrients & $\begin{array}{l}\text { Anti-Inflammatory Diet } \\
\qquad(n=13)\end{array}$ & $\begin{array}{l}\text { Pro-Inflammatory Diet } \\
\qquad(n=77)\end{array}$ & $p$ Value \\
\hline Energy (kcal) & $2043.7(656.1)$ & $1820.3(602.4)$ & 0.239 \\
\hline Protein $(\mathrm{g})$ & $85.1(33.8)$ & $74.4(27.2)$ & 0.219 \\
\hline Total fat (g) & $81.8(34.1)$ & $72.8(23.5)$ & 0.252 \\
\hline Carbohydrate (g) & $265.2(149.4)$ & $214.4(86.6)$ & 0.093 \\
\hline Fiber $(\mathrm{g})$ & $42.9(50.1)$ & $14.7(6.4)$ & $<0.000$ \\
\hline Iron (mg) & $30.1(32.9)$ & $14.4(9.3)$ & 0.001 \\
\hline Zinc (mg) & $13.2(4.5)$ & $8.9(5.2)$ & 0.008 \\
\hline Magnesium (mg) & $896.5(699.8)$ & $462.5(575.8)$ & 0.020 \\
\hline Vitamin A (RE) & $1183.1(946.9)$ & $657.1(647.3)$ & 0.016 \\
\hline Vitamin C (mg) & $146.6(56.2)$ & $69.6(58.3)$ & $<0.000$ \\
\hline Thiamin (mg) & $5.0(5.4)$ & $1.7(1.3)$ & $<0.000$ \\
\hline Riboflavin (mg) & $3.2(4.9)$ & $1.2(0.5)$ & $<0.000$ \\
\hline Niacin (mg) & $28.2(28.6)$ & $15.3(6.3)$ & 0.001 \\
\hline Saturated fatty acid (g) & $19.6(10.3)$ & $19.0(9.1)$ & 0.841 \\
\hline Mono-unsaturated fatty acid (g) & $23.7(17.0)$ & $18.3(8.2)$ & 0.080 \\
\hline Polyunsaturated fatty acid (g) & $39.1(75.1)$ & $19.2(29.5)$ & 0.096 \\
\hline Cholesterol (mg) & $178.9(112.4)$ & $250.8(199.8)$ & 0.228 \\
\hline Trans fat $(\mathrm{g})$ & $0.2(0.8)$ & $0.4(2.8)$ & 0.854 \\
\hline Omega 6 (g) & $33.7(69.8)$ & $21.1(57.1)$ & 0.492 \\
\hline Omega 3 (g) & $2.3(1.8)$ & $1.8(0.6)$ & 0.046 \\
\hline Vitamin B6 (mg) & $9.7(21.6)$ & $0.9(0.4)$ & $<0.000$ \\
\hline Selenium $(\mu \mathrm{g})$ & $59.3(35.6)$ & $56.0(44.3)$ & 0.806 \\
\hline Folic acid (mg) & $951.5(2283.9)$ & $34.9(57.6)$ & $<0.000$ \\
\hline Vitamin B12 $(\mu \mathrm{g})$ & $11.6(23.2)$ & $2.5(1.91)$ & 0.001 \\
\hline Beta Carotene $(\mu \mathrm{g})$ & $2824.8(2195.1)$ & $1458.7(1986.2)$ & 0.031 \\
\hline Vitamin E (mg) & $7.5(4.5)$ & $3.9(2.2)$ & $<0.000$ \\
\hline Vitamin D $(\mu \mathrm{g})$ & $4.8(7.5)$ & $2.5(2.0)$ & 0.028 \\
\hline Caffeine $(\mathrm{g})$ & $0.7(2.3)$ & $0.2(1.2)$ & 0.299 \\
\hline
\end{tabular}

Data are shown as mean (SD). 
Table 3 shows partial correlations adjusted for age and gender. Lower DII score (anti-inflammatory diet) was inversely correlated with plasma triglyceride levels $(r=-0.354, p<0.05)$, glucose $(r=-0.422$, $p<0.05)$, MetScore $(r=-0.228, p<0.05)$, and PWV $(r=-0.437, p<0.05)$ and positively correlated with FMD $(r=0.261, p<0.05)$. On the contrary, higher DII score (pro-inflammatory diet) showed a positive relationship with MetScore $(r=0.410, p<0.05)$ and a negative relationship with FMD $(r=-0.233, p<0.05)$. Forty percent of the subjects had a MetScore $\geq 1$, showing statistically significant differences among the categories of the DII categories. An anti-inflammatory diet was inversely correlated with percentage of fat tissue and total cholesterol values; however, these associations were not statistically significant.

Table 3. Partial correlations between percentage of fat, metabolic markers, and endothelial function according to the categories of the DII.

\begin{tabular}{ccc}
\hline Characteristic & $\begin{array}{c}\text { Anti-Inflammatory Diet } \\
(\boldsymbol{n}=\mathbf{1 3})\end{array}$ & $\begin{array}{c}\text { Pro-Inflammatory Diet } \\
(\boldsymbol{n}=\mathbf{7 7})\end{array}$ \\
\hline DXA total tissue $(\%$ fat) & -0.122 & 0.111 \\
TC $(\mathrm{mg} / \mathrm{dL})$ & -0.210 & 0.010 \\
Triglycerides $(\mathrm{mg} / \mathrm{dL})$ & $-0.354^{*}$ & -0.009 \\
HDL-C (mg/dL) & -0.100 & 0.028 \\
LDL-C (mg/dL) & 0.350 & -0.084 \\
Glucose (mg/dL) & $-0.422^{*}$ & -0.228 \\
MetScore & $-0.282^{*}$ & $0.410^{*}$ \\
HbAc1 $(\%)$ & 0.004 & 0.090 \\
FMDn $(\%)$ & $0.261^{*}$ & $-0.233 *$ \\
PWV (m/s) & $-0.437^{*}$ & 0.014 \\
Aortic systolic pressure (mm Hg) & -0.271 & -0.126 \\
Aortic pulse pressure (mm Hg) & -0.271 & -0.055 \\
Brachial augmentation index (\%) & -0.300 & -0.209 \\
Aortic augmentation index $(\%)$ & -0.299 & -0.064 \\
MAP (mm Hg) & -0.011 & 0.079 \\
\hline
\end{tabular}

$* p<0.05$ through Pearson's correlation. TC: total cholesterol; HDL-C: high-density lipoprotein-cholesterol; LDL-C: low-density lipoprotein cholesterol; Hb1Ac: glycated hemoglobin; FMD: flow-mediated vasodilation; PWV: pulse wave velocity; MAP: mean arterial pressure. The MetScore was calculated from the sum of the typified residuals $(\mathrm{Z})$ of cardiovascular risk variables: $\left(\left(\sigma^{\top} 40\right.\right.$ or $\left.\left.\$ 50-\mathrm{HDL}-\mathrm{C}\right) / \mathrm{SD} \times(-1)\right)+(($ triglycerides -150$) / \mathrm{SD})+$ $(($ glucose -100$) / S D)+\left(\left(C C-\sigma^{2} 94\right.\right.$ or 980$\left.) / S D\right)+((M A P-100) / S D$, adjusted for gender and age.

\section{Discussion}

Adherence to a healthy dietary pattern has been postulated as a determinant factor in regulating inflammatory markers [6,24]. Despite previous research have reported that the DII was associated with several inflammatory processes including obesity or certain cancers, this study, the first of its kind, investigated the relationship between the DII and cardiometabolic risk parameters was investigated in a cohort of overweight/obese and sedentary adults from Bogotá, Colombia. Our data demonstrate that an anti-inflammatory diet was significantly associated with higher HDL-C and FMD values, as well as lower $\mathrm{Hb} 1 \mathrm{Ac}$ and MetScore values, after adjusting for age and gender, thereby supporting the benefits of an anti-inflammatory diet in regard to parameters related to CVD.

To the best of our knowledge, this is the first study to evaluate the association between the DII and markers of endothelial function. Our results indicate that a more anti-inflammatory diet profile is associated with improved endothelial function, showing an inverse relationship with PWV and a positive relationship with FMD. These findings were in concordance with previous studies in which the association between healthy dietary patterns and parameters of endothelial function was investigated $[8,10,25,26]$. Rallidis et al. [25] demonstrated that close adherence to a Mediterranean diet in subjects with abdominal obesity increases FMD and decreases diastolic blood pressure (DBP) and insulin resistance (HOMA-IR). Similarly, the Mediterranean-style dietary pattern improved markers of endothelial function in patients with metabolic syndrome [26]. These data are in line with a recent 
meta-analysis that found that a Mediterranean diet reduces inflammation and improves endothelial function [10]. Furthermore, a lower intake of fiber, polyunsaturated fats, and vegetable protein and a higher intake of cholesterol were associated with increasing impairment of endothelial function in patients with type I diabetes [27]. Interestingly, a prospective study conducted by our research group in a Colombian population supported the contribution of postprandial lipemia to endothelial dysfunction [8].

With regard to conventional cardiovascular risk factors, we observed that an anti-inflammatory diet was related to higher HDL-C and lower Hb1Ac levels. Furthermore, correlation analysis identified that an increased anti-inflammatory potential of diet was inversely associated with plasma glucose and triglyceride levels. These results are in line with data from the Supplémentation en Vitamines et Minéraux AntioXydants (SU.VI.MAX) study conducted in a cohort of 3726 subjects, which demonstrated that a pro-inflammatory diet was associated with higher triglyceride and lower HDL-C levels [16]. Similarly, Sokol et al. reported an inverse relationship between the DII and HDL-C in a Polish population of 3862 participants [28]. Taking into account our association findings and the above lines of evidence, a pro-inflammatory diet might have a negative effect on the cardiometabolic risk profile across different populations [29-32].

On the other hand, this study identified an inverse association between an anti-inflammatory diet and the cardiometabolic risk score (MetScore). Previous works have explored the relationship between the DII and components of metabolic syndrome, yielding inconsistent conclusions $[16,28,33]$. In the SU.VI.MAX study, the odds of metabolic syndrome were $39 \%$ higher among subjects with a pro-inflammatory diet than in those with an anti-inflammatory diet [16]. Conversely, other authors have reported a lack of association between the DII and the MetScore [28,33]. It is interesting to note that in our study the prevalence of metabolic syndrome was $40 \%$, whereas in the above-mentioned studies it was $30 \%$ and $28 \%$, respectively. Thus, the contradictory results may be explained by the differences in the prevalence of metabolic syndrome across study cohorts.

The mechanisms by which an anti-inflammatory diet may regulate low-grade inflammation in cardiometabolic diseases are not certain. Nonetheless, it has been hypothesized that unhealthy dietary patterns with pro-inflammatory properties could trigger an innate immune response related to an increased production of pro-inflammatory cytokines and reduced production of anti-inflammatory cytokines, promoting states of chronic inflammation and consequently an increased risk of endothelial dysfunction, metabolic syndrome, and CVD [34,35].

In this study, we reported no significant differences in any anthropometric parameters or body composition variables among the categories of the DII. It is worth noting that we evaluated, for the first time, the possible relationship between the DII and measurements of body composition using a DXA device. Although the Prevención con Dieta Mediterránea (PREDIMED) study demonstrated significant associations between the DII and anthropometric data, only BMI, WC, and WHtR variables were investigated [15]. Moreover, the fact that the participants included in this study had similar anthropometric characteristics due to the inclusion criteria could explain the lack of significant associations reported in this study. Hence, further studies conducted in populations with heterogeneous anthropometric variables are needed to clarify this issue.

The present study has some limitations. First, due to its cross-sectional design, no causal conclusions can be drawn. Secondly, the DII was calculated from $24 \mathrm{~h}$ dietary records. Although the literature supports its use as a pertinent method for assessing nutrient intake, under-reporting of food intake is a limiting factor in self-reported questionnaires [36]. In order to improve the accuracy of the food descriptions, data entries were checked by a nutritionist and standard household measures were used. Another potential limitation is the major difference in sample size identified between anti-inflammatory diet group $(n=13)$ and pro-inflammatory diet group $(n=77)$. Finally, the DII score was calculated based on 28 of the 45 nutritional parameters of the original DII. The rest of the dietary components were not included due to their low self-reporting. Nevertheless, a previous study has 
indicated that their absence has no effect on DII scores, since these dietary components are not usually consumed by the population [37].

On the other hand, the main strength of the present study is that it is the first to investigate the relationship between the inflammatory potential of diet, as measured by the DII, and cardiometabolic risk parameters in a Latin American population. Since there have been no published studies conducted in populations of South and Central America, this could imply that our findings may not be generalizable to those reported in other populations with different dietary habits. Future population-based studies, and especially longitudinal studies, are required to evaluate the discriminatory power of the DII in Colombian subjects with different criteria and cardiovascular markers.

\section{Conclusions}

In summary, our results suggest that an increased anti-inflammatory potential of diet, as measured by the DII, was associated with an improved cardiometabolic profile. These findings underline the importance of promoting anti-inflammatory nutrition as an effective strategy for preventing CVD.

Acknowledgments: The authors would like to acknowledge Center for Measurement Studies in Physical Activity (CEMA) and to Universidad del Rosario for the financial and scientific support.

Author Contributions: Robinson Ramírez-Vélez, Claudia Marcela Camargo-Ramos and Jorge Enrique Correa-Bautista conceived designed the study and analyzed the data; Robinson Ramírez-Vélez and María Correa-Rodríguez analyzed the data and wrote the paper. All authors read and approved the final manuscript.

Conflicts of Interest: The authors declare no conflict of interest.

$\begin{array}{ll}\text { Abbreviations } \\ \text { BMI } & \text { Body mass index } \\ \text { CVD } & \text { Cardiovascular disease } \\ \text { DBP } & \text { Diastolic blood pressure } \\ \text { DII } & \text { Dietary inflammatory index } \\ \text { DXA } & \text { Dual-energy X-ray absorptiometry } \\ \text { FMD } & \text { Flow-mediated dilation } \\ \text { Hb1Ac } & \text { Glycosylated hemoglobin } \\ \text { HC } & \text { Hip circumference } \\ \text { HDL-C } & \text { High-density lipoprotein-cholesterol } \\ \text { LDL-C } & \text { Low-density lipoprotein-cholesterol } \\ \text { MAP } & \text { Mean arterial pressure } \\ \text { MetScore } & \text { Cardiometabolic risk score } \\ \text { PWV } & \text { Pulse wave velocity } \\ \text { SBP } & \text { Systolic blood pressure } \\ \text { TC } & \text { Total cholesterol } \\ \text { TG } & \text { Triglycerides } \\ \text { WC } & \text { Waist circumference }\end{array}$

\section{References}

1. Ruiz-Núñez, B.; Dijck-Brouwer, D.J.; Muskiet, F.A. The relation of saturated fatty acids with low-grade inflammation and cardiovascular disease. J. Nutr. Biochem. 2016, 36, 1-20. [CrossRef] [PubMed]

2. Golia, E.; Limongelli, G.; Natale, F.; Fimiani, F.; Maddaloni, V.; Pariggiano, I.; Bianchi, R.; Crisci, M.; D'Acierno, L.; Giordano, R. Inflammation and cardiovascular disease: From pathogenesis to therapeutic target. Curr. Atheroscler. Rep. 2014, 16, 1-7. [CrossRef] [PubMed]

3. Neale, E.; Batterham, M.; Tapsell, L.C. Consumption of a healthy dietary pattern results in significant reductions in c-reactive protein levels in adults: A meta-analysis. Nutr. Res. 2016, 36, 391-401. [CrossRef] [PubMed] 
4. Alissa, E.M.; Ferns, G.A. Dietary fruits and vegetables and cardiovascular diseases risk. Crit. Rev. Food Sci. Nutr. 2017, 57, 1950-1962. [CrossRef] [PubMed]

5. Hermsdorff, H.H.M.; Zulet, M.Á.; Bressan, J.; Martínez, J.A. Effect of diet on the low-grade and chronic inflammation associated with obesity and metabolic syndrome. Endocrinol. Nutr. 2008, 55, 409-419. [CrossRef]

6. Barbaresko, J.; Koch, M.; Schulze, M.B.; Nothlings, U. Dietary pattern analysis and biomarkers of low-grade inflammation: A systematic literature review. Nutr. Rev. 2013, 71, 511-527. [CrossRef] [PubMed]

7. Cuevas, A.M.; Germain, A.M. Diet and endothelial function. Biol. Res. 2004, 37, 225-230. [CrossRef] [PubMed]

8. Ramírez-Vélez, R. Postprandial lipemia induces endothelial dysfunction and higher insulin resistance in healthy subjects. Endocrinol. Nutr. 2011, 58, 529-535. [CrossRef] [PubMed]

9. Esposito, K.; Ciotola, M.; Giugliano, D. Mediterranean diet, endothelial function and vascular inflammatory markers. Public Health Nutr. 2006, 9, 1073-1076. [CrossRef] [PubMed]

10. Schwingshackl, L.; Hoffmann, G. Mediterranean dietary pattern, inflammation and endothelial function: A systematic review and meta-analysis of intervention trials. Nutr. Metab. Cardiovasc. Dis. 2014, 24, 929-939. [CrossRef] [PubMed]

11. Ricker, M.A.; Haas, W.C. Anti-inflammatory diet in clinical practice: A review. Nutr. Clin. Prac. 2017, 0884533617700353. [CrossRef] [PubMed]

12. Shivappa, N.; Steck, S.E.; Hurley, T.G.; Hussey, J.R.; Hébert, J.R. Designing and developing a literature-derived, population-based dietary inflammatory index. Public Health Nutr. 2014, 17, 1689-1696. [CrossRef] [PubMed]

13. Ruiz-Canela, M.; Bes-Rastrollo, M.; Martínez-González, M.A. The role of dietary inflammatory index in cardiovascular disease, metabolic syndrome and mortality. Int. J. Mol. Sci. 2016, 17, 1265. [CrossRef] [PubMed]

14. Hebert, J.R.; Shivappa, N.; Tabung, F.K.; Steck, S.E.; Wirth, M.D.; Hurley, T.G. On the use of the dietary inflammatory index in relation to low-grade inflammation and markers of glucose metabolism in the cohort study on diabetes and atherosclerosis maastricht (codam) and the hoorn study. Am. J. Clin. Nutr. 2014, 99, 1520. [CrossRef] [PubMed]

15. Ruiz-Canela, M.; Zazpe, I.; Shivappa, N.; Hébert, J.R.; Sánchez-Tainta, A.; Corella, D.; Salas-Salvadó, J.; Fitó, M.; Lamuela-Raventós, R.M.; Rekondo, J.; et al. Dietary inflammatory index and anthropometric measures of obesity in a population sample at high cardiovascular risk from the predimed (prevención con dieta mediterránea) trial. Br. J. Nutr. 2015, 113, 984-995. [CrossRef] [PubMed]

16. Neufcourt, L.; Assmann, K.E.; Fezeu, L.K.; Touvier, M.; Graffouillère, L.; Shivappa, N.; Hébert, J.R.; Wirth, M.D.; Hercberg, S.; Galan, P.; et al. Prospective association between the dietary inflammatory index and cardiovascular diseases in the supplémentation en vitamines et minéraux antioxydants (su.Vi.Max) cohort. J. Am. Heart Assoc. 2015, 5, e002735. [CrossRef] [PubMed]

17. Ramírez-Vélez, R.; Hernandez, A.; Castro, K.; Tordecilla-Sanders, A.; González-Ruíz, K.; Correa-Bautista, J.E.; Izquierdo, M.; García-Hermoso, A. High intensity interval-vs resistance or combined-training for improving cardiometabolic health in overweight adults (cardiometabolic hiit-rt study): Study protocol for a randomised controlled trial. Trials 2016, 17, 298. [CrossRef] [PubMed]

18. Alberti, K.G.; Eckel, R.H.; Grundy, S.M.; Zimmet, P.Z.; Cleeman, J.I.; Donato, K.A.; Fruchart, J.C.; James, W.P.; Loria, C.M.; Smith, S.C.J. Harmonizing the metabolic syndrome: A joint interim statement of the international diabetes federation task forceon epidemiology and prevention; national heart, lung, and blood institute; American heart association; world heartfederation; international atherosclerosis society; and international association for the study of obesity. Circulation 2009, 120, 1640-1645. [PubMed]

19. López-Albán, C.A.; Ramirez-Vélez, R.; Sanchez-Gallardo, C.E.; Marmolejo, L.C. Características antropométricas y funcionales de individuos físicamente activos. Iatreia 2008, 21, 121-128. (In Spanish)

20. World Health Organization. Obesity: Preventing and Managing the Global Epidemic; World Health Organization: Geneva, Switzerland, 2000.

21. Friedewald, W.T.; Levy, R.I.; Fredrickson, D.S. Estimation of the concentration of low-density lipoprotein cholesterol in plasma, without use of the preparative ultracentrifuge. Clin. Chem. 1972, 18, 499-502. [PubMed] 
22. Corretti, M.; Anderson, T.; Benjamin, E.; Celermajer, D.; Charbonneau, F.; Creager, M.; Deanfield, J.; Drexler, H.; Gerhard-Herman, M.; Herrington, D. International brachial artery reactivity task force. Guidelines for the ultrasound assessment of endothelial-dependent flow-mediated vasodilation of the brachial artery: A report of the international brachial artery reactivity task force. J. Am. Coll. Cardiol. 2002, 39, 257-265. [CrossRef]

23. Stoner, L.; Young, J.M.; Fryer, S. Assessments of arterial stiffness and endothelial function using pulse wave analysis. Int. J. Vasc. Med. 2012, 2012. [CrossRef] [PubMed]

24. Kuczmarski, M.F.; Mason, M.A.; Allegro, D.; Zonderman, A.B.; Evans, M.K. Research: Diet quality is inversely associated with c-reactive protein levels in urban, low-income African-American and white adults. J. Acad. Nutr. Diet. 2013, 113, 1620-1631. [CrossRef] [PubMed]

25. Rallidis, L.S.; Lekakis, J.; Kolomvotsou, A.; Zampelas, A.; Vamvakou, G.; Efstathiou, S.; Dimitriadis, G.; Raptis, S.A.; Kremastinos, D.T. Close adherence to a mediterranean diet improves endothelial function in subjects with abdominal obesity. Am. J. Clin. Nutr. 2009, 90, 263-268. [CrossRef] [PubMed]

26. Esposito, K.; Marfella, R.; Ciotola, M.; Di Palo, C.; Giugliano, F.; Giugliano, G.; D’Armiento, M.; D’Andrea, F.; Giugliano, D. Effect of a mediterranean-style diet on endothelial dysfunction and markers of vascular inflammation in the metabolic syndrome-A randomized trial. JAMA 2004, 292, 1440-1446. [CrossRef] [PubMed]

27. Van Bussel, B.C.T.; Soedamah-Muthu, S.S.; Henry, R.M.A.; Schalkwijk, C.G.; Ferreira, I.; Chaturvedi, N.; Toeller, M.; Fuller, J.H.; Stehouwer, C.D.A. Unhealthy dietary patterns associated with inflammation and endothelial dysfunction in type 1 diabetes: The eurodiab study. Nutr. Metab. Cardiovasc. Dis. 2013, 23, 758-764. [CrossRef] [PubMed]

28. Sokol, A.; Wirth, M.D.; Manczuk, M.; Shivappa, N.; Zatonska, K.; Hurley, T.G.; Hébert, J.R. Association between the dietary inflammatory index, waist-to-hip ratio and metabolic syndrome. Nutr. Res. 2016, 36, 1298-1303. [CrossRef] [PubMed]

29. Ramallal, R.; Toledo, E.; Martínez-González, M.A.; Hernández-Hernández, A.; García-Arellano, A.; Shivappa, N.; Hébert, J.R.; Ruiz-Canela, M. Dietary inflammatory index and incidence of cardiovascular disease in the sun cohort. PLoS ONE 2015, 10, e0135221. [CrossRef] [PubMed]

30. O’Neil, A.; Shivappa, N.; Jacka, F.N.; Kotowicz, M.A.; Kibbey, K.; Hebert, J.R.; Pasco, J.A. Pro-inflammatory dietary intake as a risk factor for cvd in men: A 5-year longitudinal study. Br. J. Nutr. 2015, 114, 2074-2082. [CrossRef] [PubMed]

31. Garcia-Arellano, A.; Ramallal, R.; Ruiz-Canela, M.; Salas-Salvadó, J.; Corella, D.; Shivappa, N.; Schröder, H.; Hébert, J.R.; Ros, E.; Gómez-Garcia, E.; et al. Dietary inflammatory index and incidence of cardiovascular disease in the predimed study. Nutrients 2015, 7, 4124-4138. [CrossRef] [PubMed]

32. Wirth, M.D.; Shivappa, N.; Hurley, T.G.; Hébert, J.R. Association between previously diagnosed circulatory conditions and a dietary inflammatory index. Nutr. Res. 2016, 36, 227-233. [CrossRef] [PubMed]

33. Wirth, M.D.; Burch, J.; Shivappa, N.; Violanti, J.M.; Burchfiel, C.M.; Fekedulegn, D.; Andrew, M.E.; Hartley, T.A.; Miller, D.B.; Mnatsakanova, A.; et al. Association of a dietary inflammatory index with inflammatory indices and metabolic syndrome among police officers. J. Occup. Environ. Med. 2014, 56, 986-989. [CrossRef] [PubMed]

34. Giugliano, D.; Ceriello, A.; Esposito, K. The effects of diet on inflammation. J. Am. Coll. Cardiol. 2006, 48, 677-685. [CrossRef] [PubMed]

35. Galland, L. Diet and inflammation. Nutr. Clin. Pract. 2010, 25, 634-640. [CrossRef] [PubMed]

36. Poslusna, K.; Ruprich, J.; de Vries, J.H.M.; Jakubikova, M.; van't Veer, P. Misreporting of energy and micronutrient intake estimated by food records and $24 \mathrm{~h}$ recalls, control and adjustment methods in practice. Br. J. Nutr. 2009, 101, S73-S85. [CrossRef] [PubMed]

37. Tabung, F.K.; Steck, S.E.; Zhang, J.J.; Ma, Y.S.; Liese, A.D.; Agalliu, I.; Hingle, M.; Hou, L.; Hurley, T.G.; Jiao, L.; et al. Construct validation of the dietary inflammatory index among postmenopausal women. Ann. Epidemiol. 2015, 25, 398-405. [CrossRef] [PubMed]

(C) 2017 by the authors. Licensee MDPI, Basel, Switzerland. This article is an open access article distributed under the terms and conditions of the Creative Commons Attribution (CC BY) license (http:// creativecommons.org/licenses/by/4.0/). 